\title{
Seasonal variation in the occurrence of planktic bivalve larvae in the Schleswig-Holstein Wadden Sea
}

\author{
Andrea Pulfrich * \\ Institut für Meereskunde; Düsternbrooker Weg 20, 24105 Kiel, Germany
}

\begin{abstract}
In the late 1980s, recruitment failures of the mussel Mytilus edulis led to economic problems in the mussel fishing and cultivation industries of northwestern Europe. As part of a collaborative study to gain a better understanding of the mechanisms affecting recruitment processes of mussels, plankton samples were collected regularly over a four-year period (1990-1993) from three stations in the Schleswig-Holstein Wadden Sea. The bivalve component of the plankton was dominated by the Solenidae, which was almost exclusively represented by Ensis americanus (= directus). $M$. edulis was the second most abundant species. Abundances of mussel larvae peaked 2 to 4 weeks after spawning maxima in the adult populations. Although variations in timing and amplitude of the total larval densities occurred, annual abundances of $M$. edulis larvae remained stable during the study period, and regional abundance differences were insignificant. A close relationship was found between peaks in larval abundance and phytoplankton blooms. Differences in larval concentrations in the ebb and the flow currents were insignificant. Planktic mussel larvae measured between $200 \mu \mathrm{m}$ and $300 \mu \mathrm{m}$, and successive cohorts were recognizable in the majority of samples. Most larvae were found to originate from local stocks, although imports from outside the area do occur.
\end{abstract}

\section{INTRODUCTION}

Successive years of failing spatfall and recruitment of the edible mussel Mytilus edulis L. (Bivalvia) on the northwestern European coast during the late 1980 s caused substantial production losses in the mussel fishing and cultivation industries. As part of an extensive study of the reproduction and recruitment of mussels in the Schleswig-Holstein Wadden Sea, detailed analyses of plankton samples from this area were conducted to provide insight into the relationship between benthic mussel communities and planktic distributions of mussel larvae in the Wadden Sea.

In contrast to the adults, the larvae of $M$. edulis undergo an extended, highly dispersive phase. It is not clear to what extent the temporal and spatial abundances of Mytilus larvae in the Wadden Sea result from spawning events of the local adult populations as described by Pulfrich (in prep.), or from immigration of larvae from the North Sea. Larval abundances may further be suggestive of subsequent settlements and recruitments, although the relationship between planktic larval abundance and subsequent spat settlements appears to be complex.

\footnotetext{
- Present address: Marine Biology Reseasch Institute, University of Cape Town, 7700 Rondebosch, South Africa
} 
In the majority of shallow-water bivalves, fertilization of large numbers of broadcastspawned gametes occurs in the water column. The resulting trochophore larvae develop into planktotrophic shelled veligers. Species identification based on shell shape and structure becomes possible with the deposition of the final larval shell. After 2 to 4 weeks in the surface waters, the veliconcha larva develops a foot and the resulting pediveliger is capable of attachment to a substrate before metamorphosing into the sessile life form (Bayne, 1976). Excellent reviews of the development, morphology and ecology of M. edulis larvae have been written by Widdows (1991) and Lutz \& Kennish (1992).

Although the seasonal variation in occurrence of bivalve larvae in the North Sea plankton has been well documented (Kändler, 1926; Werner, 1940; Rees, 1950; Heiber, 1988), assessment of local larval densities will allow comparisons between the effects of local spawning patterns and long-range larval transport caused by oceanographic conditions. As $M$. edulis was the specific subject of this study, investigations were restricted to this species, and only brief comparative references will be made to the various cooccurring bivalve species.

\section{MATERIALS AND METHODS}

The Wadden Sea is a unique and highly productive area in the German Bight, extending over an area of approximately $6000 \mathrm{~km}^{2}$ from the Netherlands to Denmark. The Schleswig-Holstein section of the Wadden Sed stretches from the Danish border in the north, to the mouth of the Elbe estuary in the south, encompassing an area of $2800 \mathrm{~km}^{2}$. Intertidal sandbanks and mudflats, bordered by shallow subtidal flats, flood bays, drainage gullies and deeper inlets and channels, extend in a zone of up to $30 \mathrm{~km}$ width from the islands and sand reefs to the shore. The wild mussel beds, and consequently the fishery, are concentrated in the regions north of the Eiderstedt peninsula, sheltered from the prevailing westerly winds by the North Frisian islands and by offshore sandbars. The tidal range in the area is about $2.7 \mathrm{~m}$ at spring tides and $1.7 \mathrm{~m}$ at neap tides. Larger tidal ranges are not infrequent during strong easterly or westerly winds. Near the inlets, this results in strong tidal currents and high water turbulence. Due to its shallow nature, the Wadden Sea has a small water volume relative to its area, and there is little large-scale water transport and exchange, as the water body washes back and forth with every tide. A residual coastal current, however, results in small-scale exchange of Wadden Sea and North Sea water during each tide (Postma, 1982).

To investigate temporal and geographic variations in the occurrence and abundance of planktic bivalve larvae, surface plankton samples were collected routinely during ebb tides, commencing in April 1990, from the seaward sections of each of three major tidal streams around the island of Amrum (Fig. 1). In the Norderaue, samples were taken every two weeks during spring and summer, and every four weeks in autumn and winter (weather permitting). The Süderaue and Hörnum Tief were sampled at monthly intervals in spring and summer only. During 1991 the flood current in the Norderaue was additionally sampled to provide a comparison of the plankton composition in the flood and ebb tides. Occasional samples were taken $10 \mathrm{~km}$ seaward of the regular sampling stations (Westvortrapptief [WVTP], Fig. 1), for comparison with the experimental samples.

Plankton samples were collected with paired bongo-nets, $20 \mathrm{~cm}$ diameter, $150 \mu \mathrm{m}$ mesh, with centres $0.5 \mathrm{~m}$ apart. The nets were towed just below the surface against the 


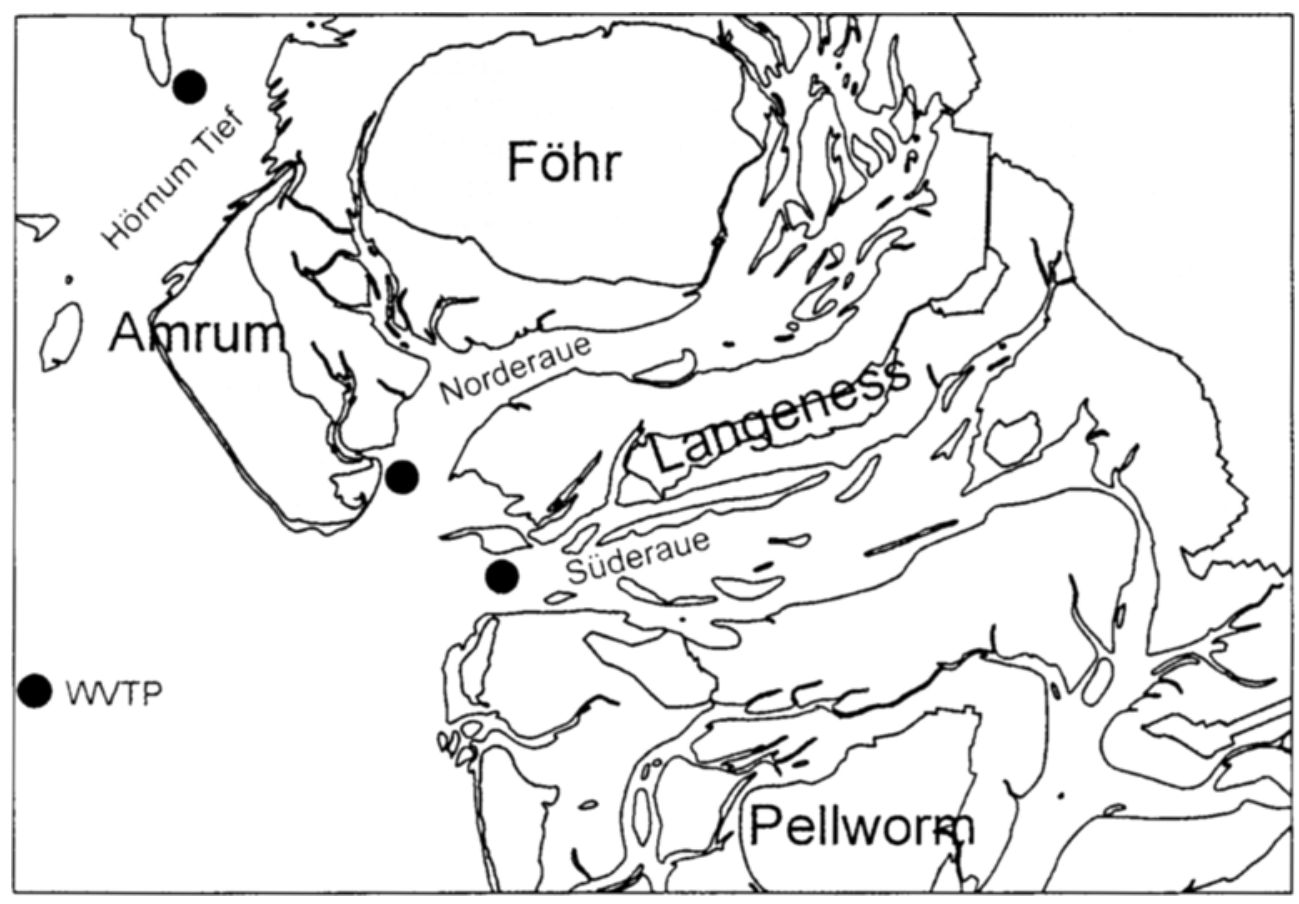

Fig. 1. Map of the study area around the island of Amrum in the Schleswig-Holstein Waclden Sea, showing the positions of the sampling stations. WVTP $=$ Westvortrapptief

current at approximately 3.5 to 4 knots (relative vessel speed), approximately $3 \mathrm{~h}$ after high tide during daylight. The irregularity of the channel bottoms made deep water tows impractical. Occasional oblique hauls were, however, taken in the Hörnum Tief for comparison with the experimental surface samples. The water volume of each sample was determined using flow meters (General Oceanics) mounted in the mouths of the nets. Three successive tows were made at each location on each sampling occasion, providing six samples per station. The three locations were sampled in succession.

The content of each net was washed into the net bag, and the concentrated sample carefully transferred to $500-\mathrm{ml}$ jars. Samples were preserved in a buffered $4 \%$ formalinseawater solution, stained with Bengal Red and analysed within 4 months to avoid degradation of the larval shells. Staining of the material was necessary due to the large quantities of sand in the plankton samples. The sand particles made sorting of unstained samples especially tedious as the larvae are of a size and colour similar to the sand grains. As preservation of the material results in the disappearance of characteristic features such as shell colour, velum shape and eye-spots, staining of the larvae did not further complicate identification. Samples which were too large for complete analysis were divided using a 10 division plankton splitter. Large planktic species were excluded by using a $300-\mu \mathrm{m}$ mesh filter, the bivalve larvae being retained on a $150-\mu \mathrm{m}$ sieve. The separated samples were assessed under a dissecting microscope, and a subsample of bivalve larvae taken for determination of species composition. The subsamples were photographed 
through a binocular photomicroscope and the genera identified from the photographs by shell shape, prominence of the umbones and larval convexity. A selection of samples was also analysed in more detail, with the assistance of Dr. K. Ocklemann (Marinebiologisk Laboratorium, Helsingør) for the construction of the species list.

The photographed subsamples were further analysed using a video camera attached to a binocular microscope. M. edulis larvae were measured from the video image using a computer-based image analysis system. Measurements were taken as the greatest dimension on a line parallel to the hinge (Bayne, 1976). Successive cohorts in each normally distributed component of the bimodal length-frequency distributions were separated using the Bhattacharya method (Bhattacharya, 1967) in the ELEFAN length-frequency analysis package (Gayanilo et al., 1989).

Although bivalves $>300 \mu \mathrm{m}$ were present in the plankton in small numbers, these were found to be post-larval drifters and were only considered in size-frequency analyses. Data were analysed after log transformation by analysis of variance, using the Scheffé range test at a $95 \%$ significance level.

\section{RESULTS}

Temporal variability in the mean numbers of bivalve larvae in three major tidal streams from 1990 to 1992 was considerable (Fig. 2). Although coefficients of variation between localities and sampling periods were variable, differences in total plankton

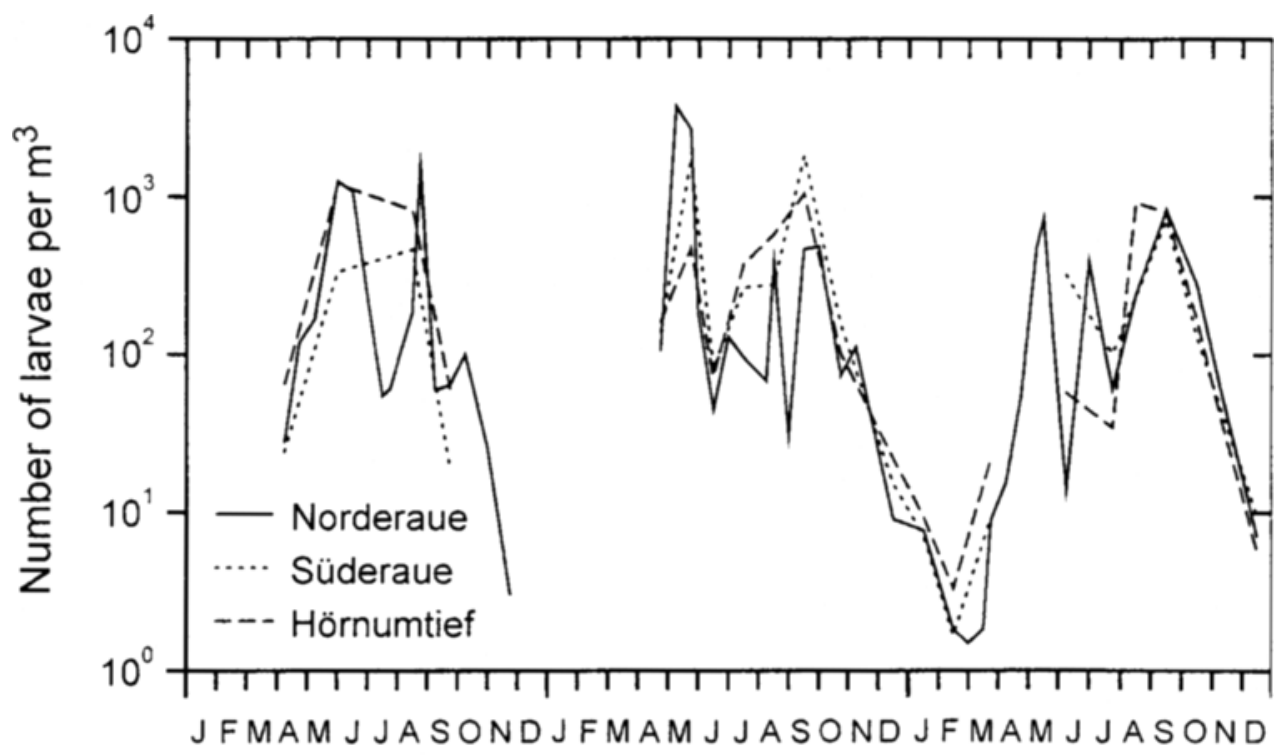

1990

1991

1992

Fig. 2. Temporal variations in the mean number of bivalve larvae present in the plankton of three major tidal streams around the island of Amrum. Sampling was conducted in the Norderaue at fortnightly intervals, in the Hörnum Tief and Süderaue at monthly intervals. Number of observations per sampling interval $=6$ 
Table 1. The bivalve mollusc larvae identified in the Schleswig-Holstein Wadden Sea plankton during this study. Taxonomy according to Hoisaeter (1986)

MYTILIDAE

Mytilus edulis

Modiolus modiolus

Linné, 1758

Linné, 1758

ANOMIIDAE

Anomia ephippium Linné,1758

LASAEIDAE

Montacuta ferruginosa Montagu, 1808

Mysella bidentata Montagu,1803

CARDIIDAE

Cerastoderma edule Linnè.1758

MACTRIDAE

Mactra corallina Linné,1758

Spisula solida Linné,1758

Spisula subtruncata da Costa, 1778

SOLENIDAE

Ensis americanus (=directus)

Ensis siliqua

Phaxas pellucidus

Conrad, 1866

Linné, 1758

Pennant, 1777

TELLINIDAE

Macoma balthica Linné, 1758

Tellina tenuis

da Costa, 1778

Tellina fabulina fabula Gmelin, 1791

DONACIDAE

Donax vittatus

da Costa, 1778

SCROBICULARIIDAE

Abra alba

Scrobicularia plana

Wood, 1802

da Costa, 1778

PETRICOLIDAE

Petricolaria pholadiformis $\quad$ Lamarck, 1818

MYIDAE

Mya arenaria

Linné, 1758

Mya truncata

Linné, 1758

CORBULIDAE

Corbula gibba

Olivi, 1792

HIATELLIDAE

Hiatella arctica Linné,1758

PHOLADIDAE

Barnea candida

Pholas dactylus

Zirfaea crispata

Linné, 1758

Linné, 1758

Linné, 1758

TEREDINIDAE

Teredo navalis Linné,1758

VENERIDAE

Dosinia sp.

Chamelea stratula 


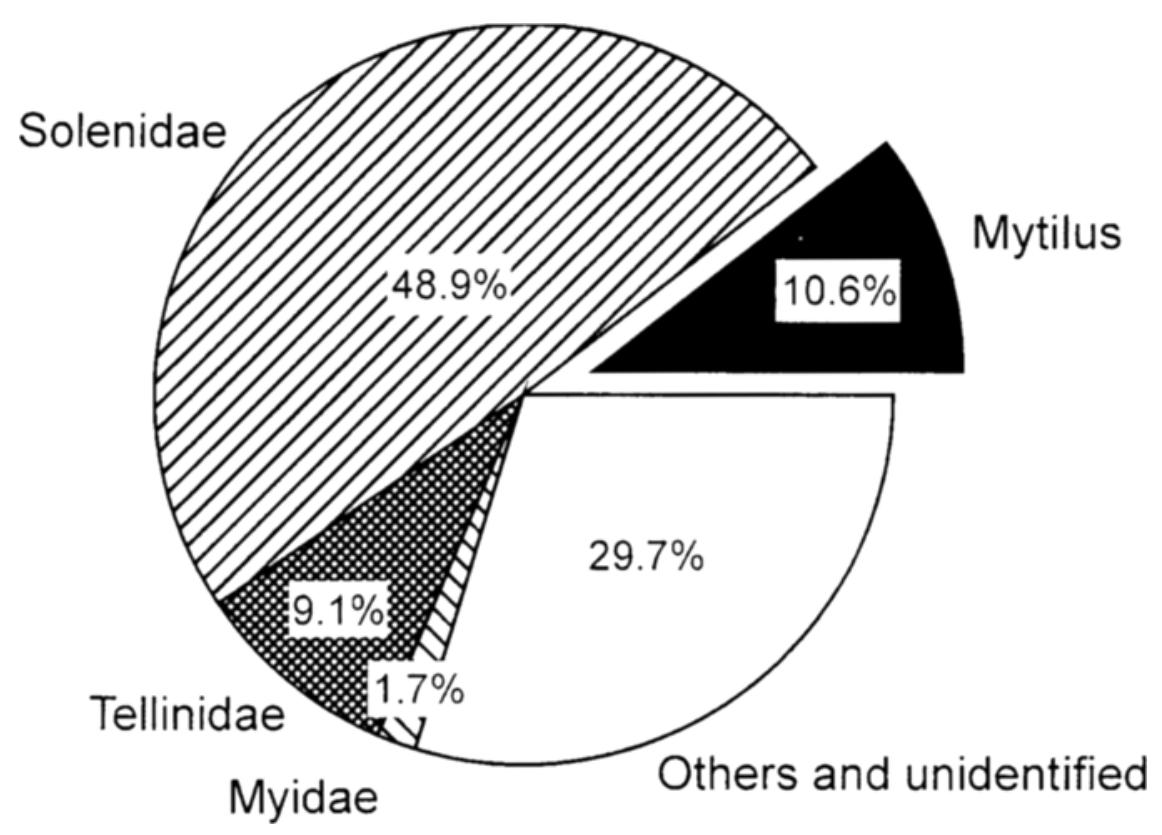

Fig. 3. Percentage larval composition of the major bivalve groups represented in the plankton of the tidal streams around the island of Amrum (number of samples $=660$ )

abundance between the three sampling locations were insignificant. At least two distinct periods of maximum larval density occurred, in late May and June, and again in August/ September. In the Norderaue where sampling was more frequent, intermediate peaks were also apparent. The high diversity of bivalve larvae in the plankton (Table 1) necessitated the grouping of allied species into their respective families for further analysis. Figure 3 shows that the Solenidae, which are almost exclusively represented by Ensis americanus (= directus), dominated the bivalve component of the plankton, with $M$. edulis as the second most abundant species.

The temporal variations of the five major bivalve groups represented in the plankton of the Norderaue, Hörnum Tief and Süderaue are illustrated in Figures 4, 5 and 6, respectively. Although variations in the timing and amplitude of total larval densities occurred, no significant differences were found between years. The overall seasonal periodicity between the groups was isomorphous, although slight temporal shifts in abundance maxima were apparent. Thus, whereas in 1990 in the Norderaue the first peaks in total abundance occurred slightly later than in successive years, the spring maximum of $M$. edulis larvae had already passed by April. In 1991, however, the Mytilus peak was observed in late May, a fortnight after the maximum in total bivalve larvae. These nuances were not detected at Hörnum Tief and Süderaue due to the less frequent sampling. When plankton sampling was conducted throughout the winter, small numbers of mussel larvae were found, even in winter.

Occasional comparative oblique hauls found slightly higher larval concentrations (total bivalves and mussels) in subsurface samples. These differences were, however, not significant at the $95 \%$ level. 


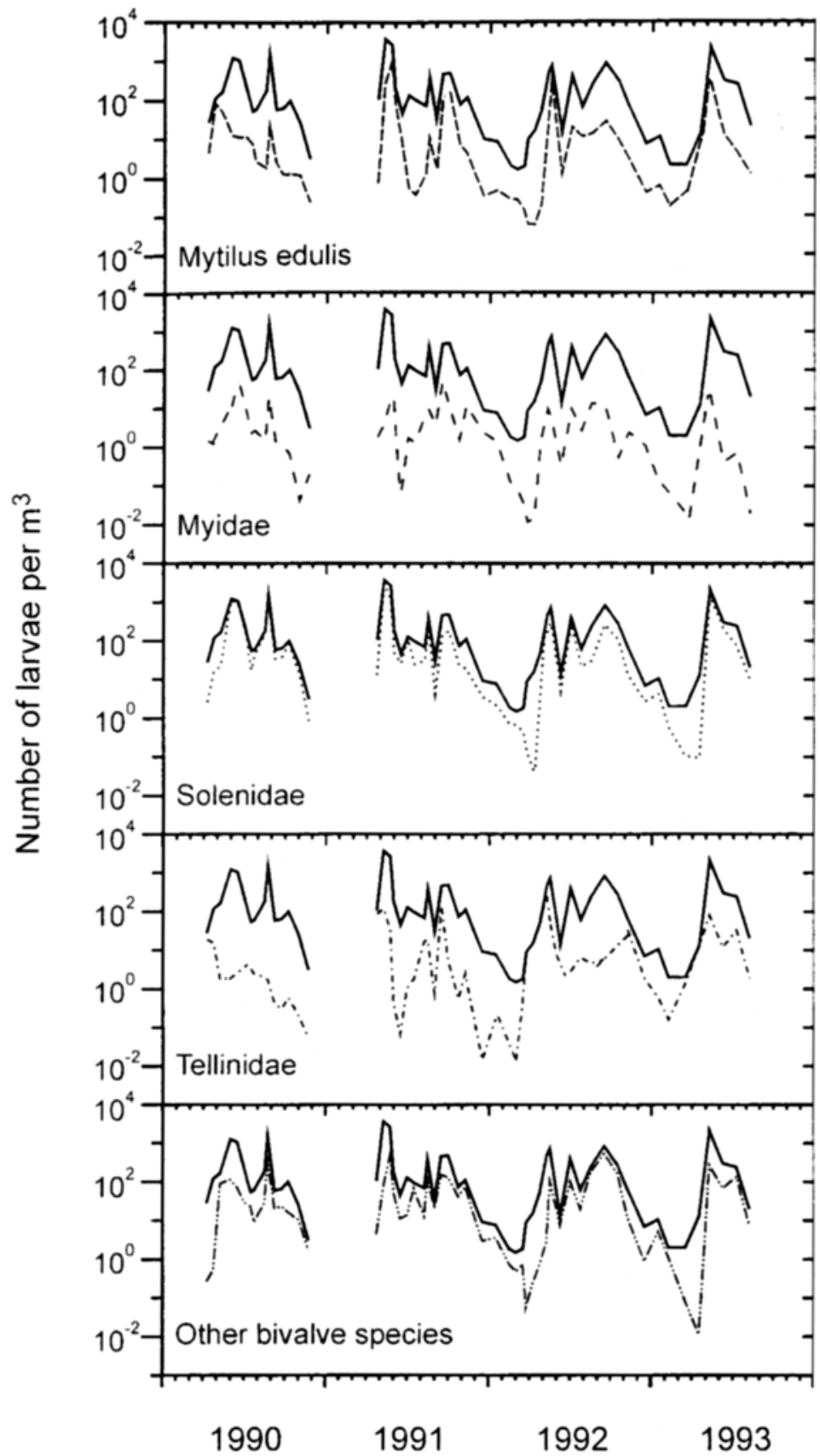

Fig. 4. Temporal variation in the total number of bivalve larvae (upper solid lines) and the larval densities of the major bivalve groups (lower dashed lines) in the Norderaue plankton. Each data point is the mean of 6 observations taken at fortnightly intervals during summer, and monthly intervals during winter 


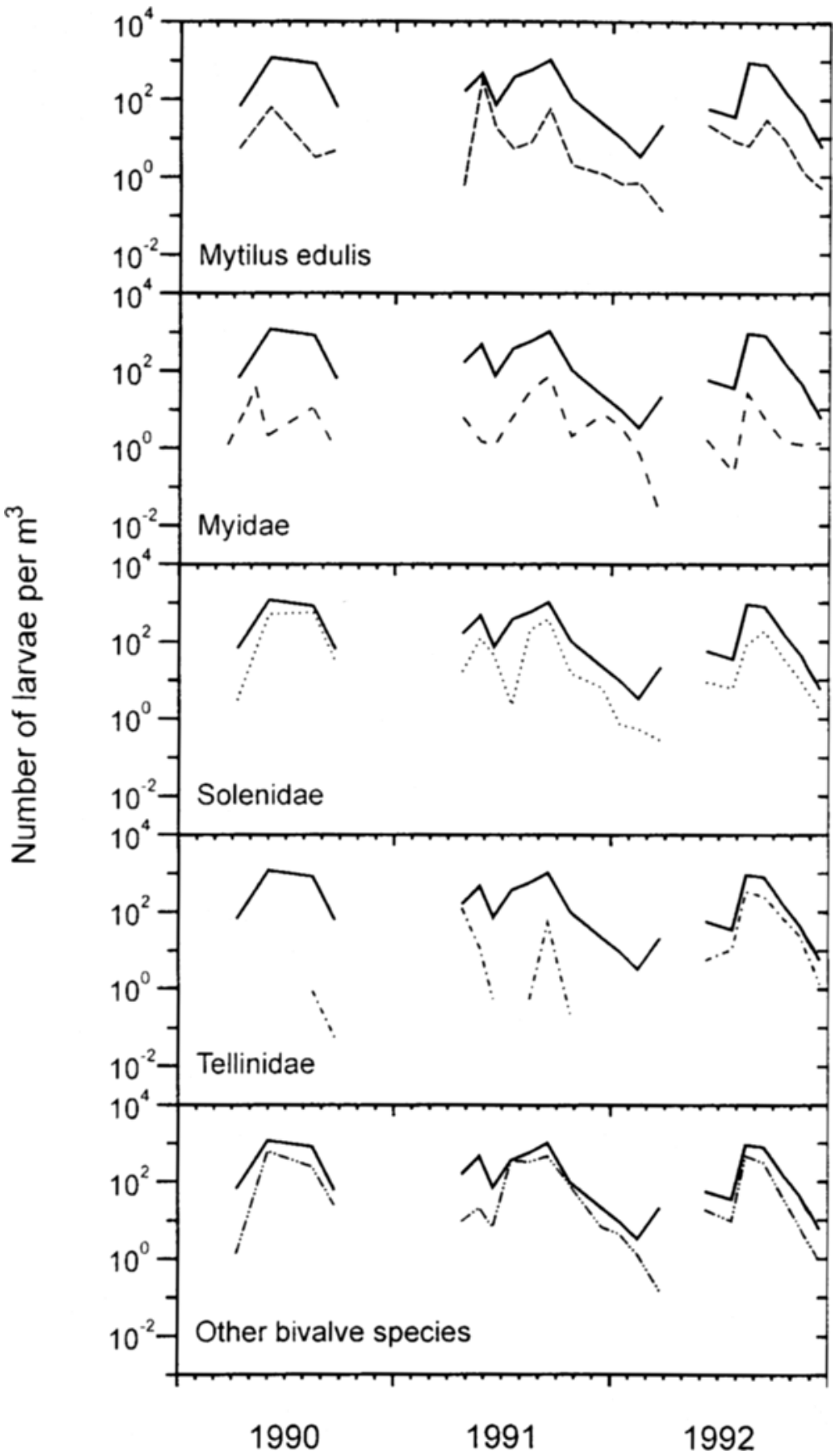

Fig. 5. Temporal variation in the total number of bivalve larvae (upper solid lines) and the larval densities of the major bivalve groups (lower dashed lines) in the Hörnum Tief plankton. Each data point is the mean of 6 observations taken at monthly intervals 


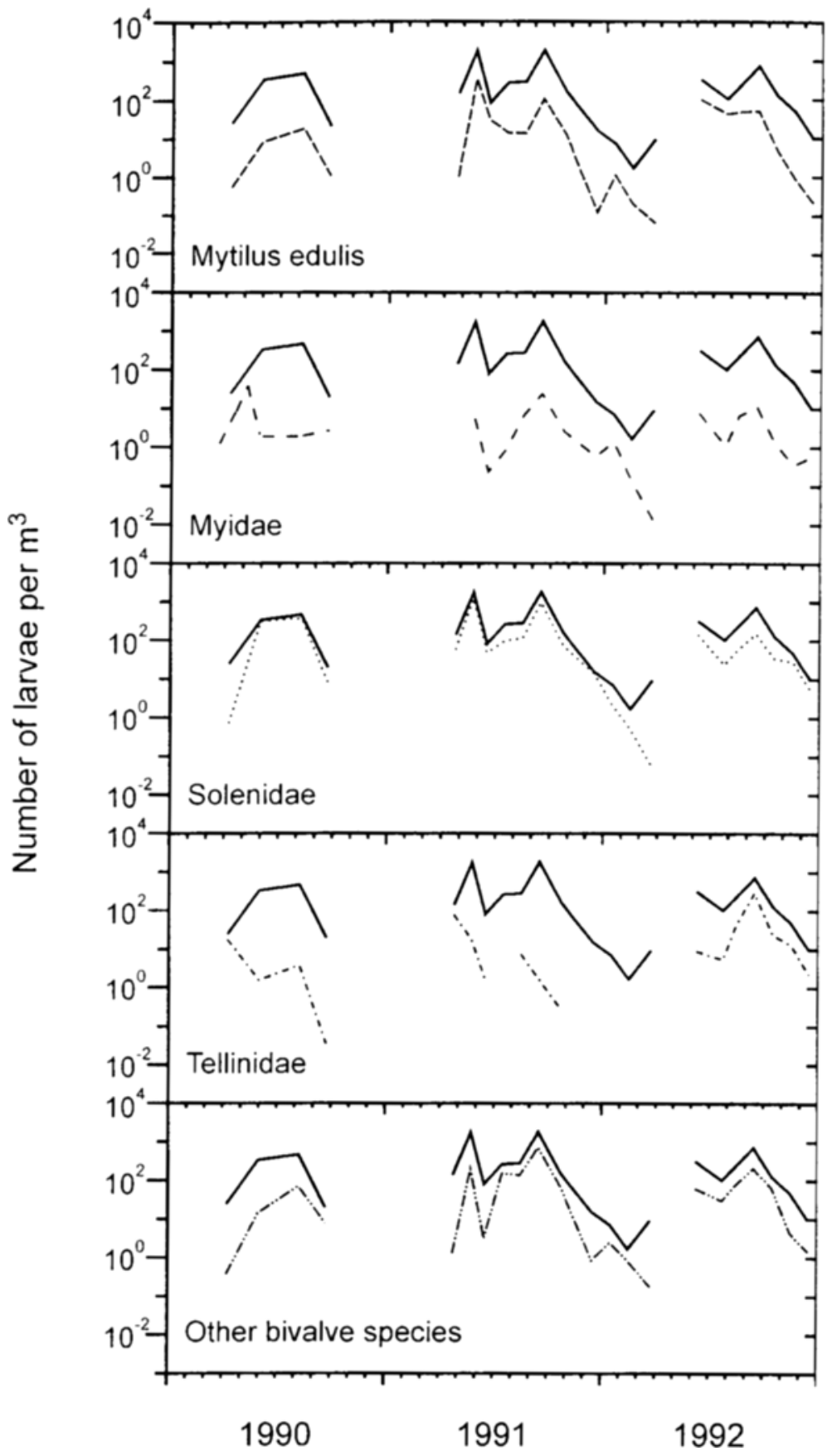

Fig. 6. Temporal variation in the total number of bivalve larvae (upper solid lines) and the larval densities of the major bivalve groups (lower dashed lines) in the Süderaue plankton. Each data point is the mean of 6 observations taken at monthly intervals 


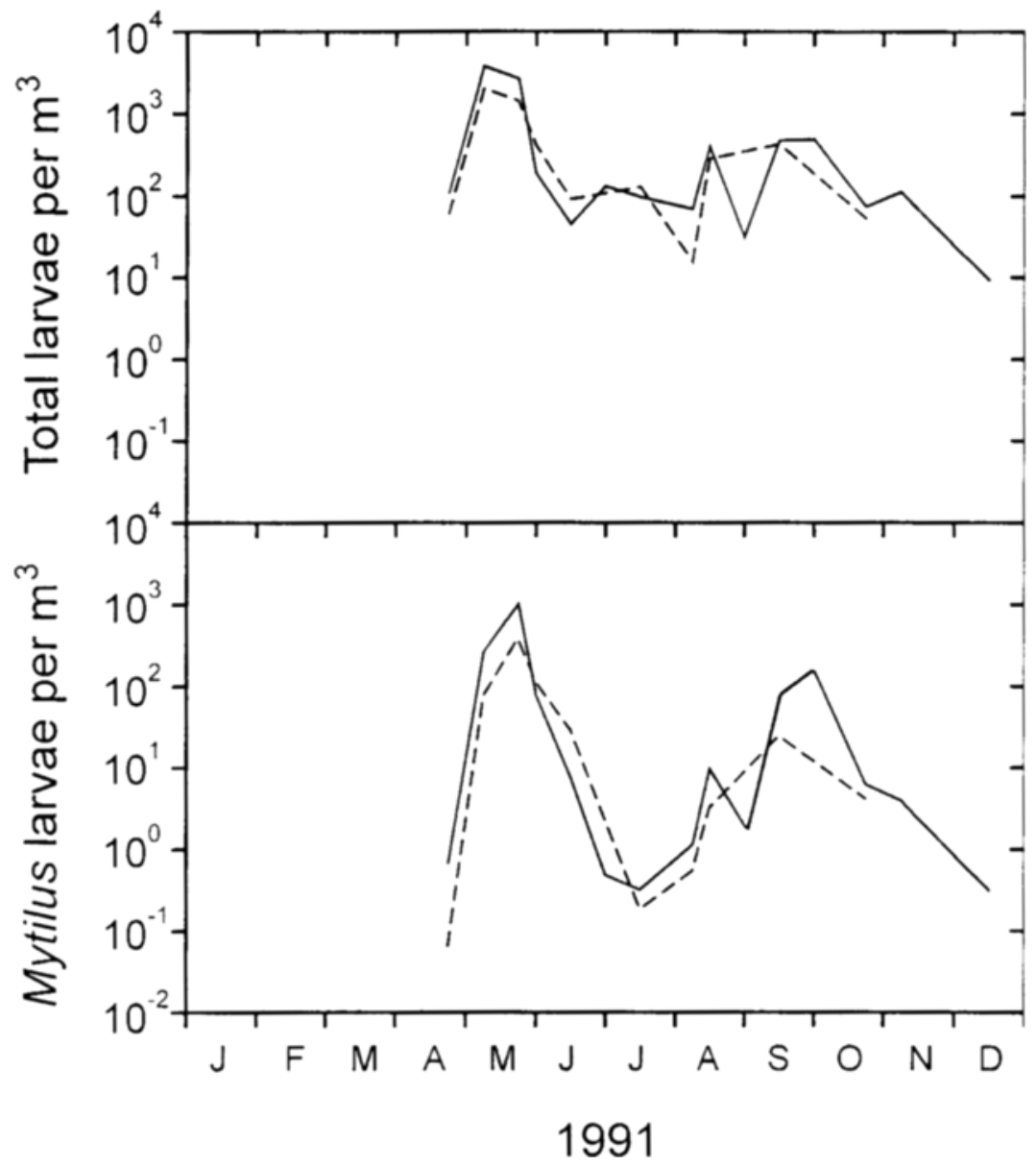

Fig. 7. Total number of bivalve larvae and mean numbers of Mytilus edulis larvae per unit volume in the ebb and flow currents in the Norderaue during 1991. Each data point is based on 6 observations taken at fortnightly intervais; -_ ebb current; - - - flow current

Although insignificant, larval abundance in the ebb current in the Norderaue was, on average, higher than on the rising tide (Fig. 7). A slight influx of $M$. edulis larvae was only observed in the period May to July, the densities being higher in the flow tide than the ebb tide. Amongst the other families, only the Tellinidae showed a marked difference in abundance between rising and falling tides, there being a significant export of larvae throughout the year.

The largest proportion of larvae measured during 1991 and 1992 were 200-300 $\mu \mathrm{m}$ in size (Fig. 8). Successive cohorts were recognizable in the majority of the samples measured. Increases in mean length over a 2-4 week period represent growth of the respective cohort during its pelagic residence. In 1991, an increase in the mean length and an increase in the length-frequency range occurred between 9th and 24th May. In early June this cohort was still recognizable at a mean size of $294 \mu \mathrm{m}$, prior to leaving the plankton 


\section{1}

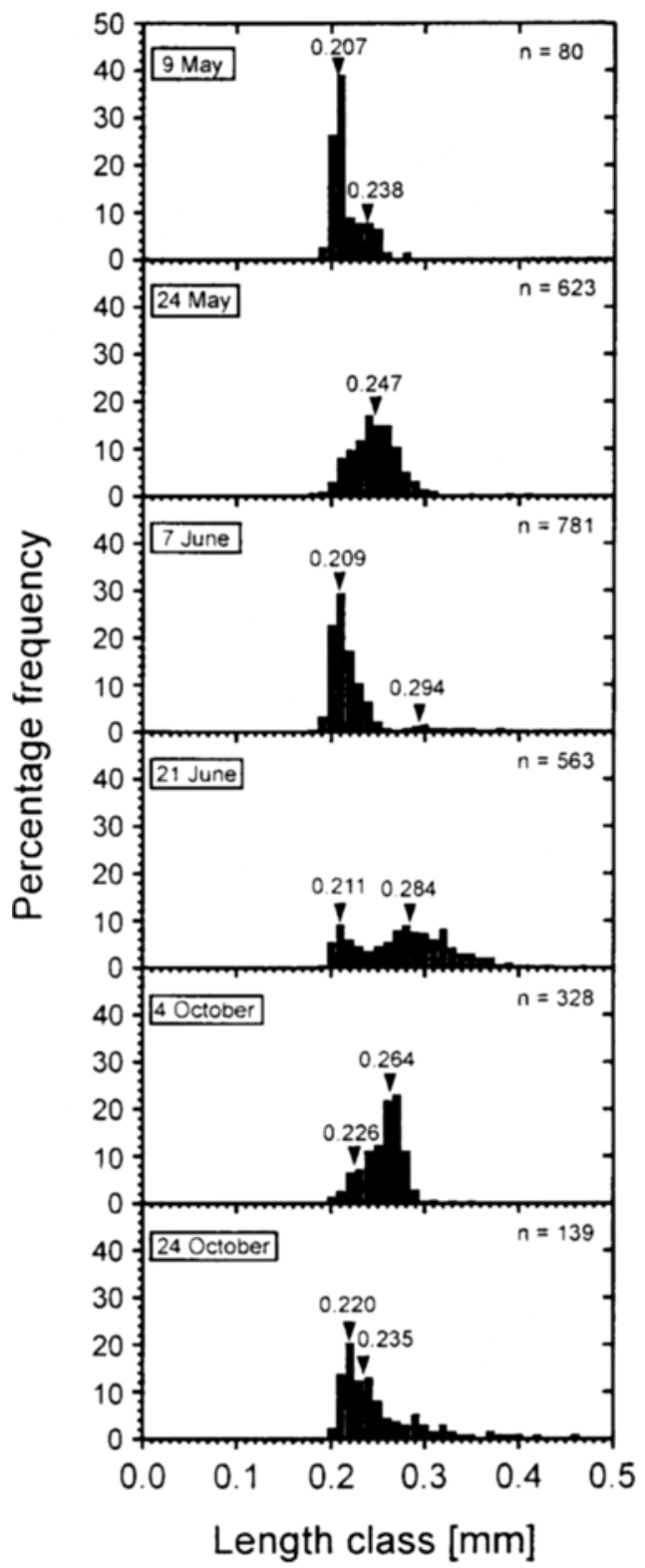

1992

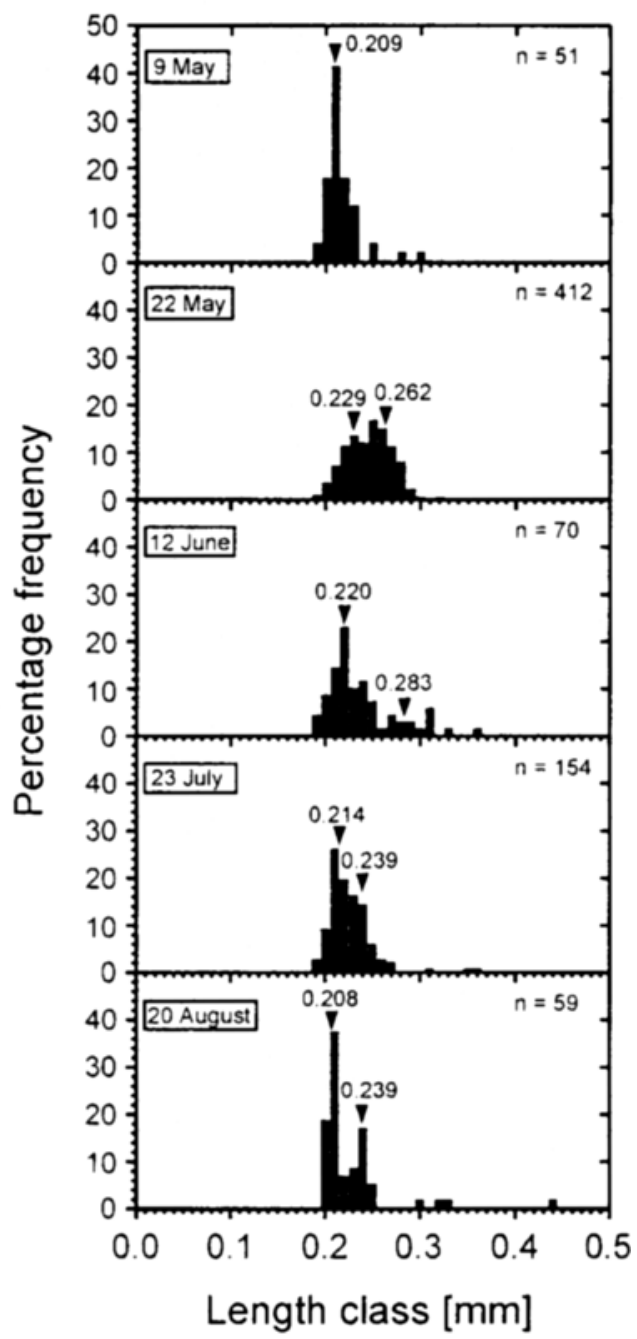

Fig. 8. Size-frequency distributions of Mytilus edulis larvae at intervals during 1991 and 1992 from the Norderaue plankton $(\mathrm{n}=$ number of larvae measured; class widths $=0.01 \mathrm{~mm}$ ). Mean size $(\mathrm{mm})$ of the first and second larval cohorts, determined by the Bhattacharya method (see text for details), are indicated 
and settling in the benthos, and a succeeding cohort (mean $=209 \mu \mathrm{m})$ appeared. The dominant second mode in late June may represent bysso-pelagic post-larvae undergoing migration in the plankton between successive attachments. Similar patterns were noted in the length distributions for October, representing larvae from the autumn abundance, and in length distributions the following year.

\section{DISCUSSION}

Identification of planktic bivalve larvae has been fraught with difficulty and controversy for almost a century (Stafford, 1912; Kändler, 1926; Nelson, 1928; Miyazaki, 1962; Werner, 1940; Jørgensen, 1946; Thorson, 1946; Sullivan, 1948; Rees, 1950; Loosanoff et al., 1966). In particular, there are no comprehensive identification guides available for North Sea species, like the photo-series of shell shapes and sizes of North American bivalve larvae published by Sullivan (1948) and Loosanoff et al. (1966). Identification methods based on valve hinge morphology or larval culture are too impractical and time consuming for long-term plankton monitoring studies, so the larval shell form descriptions of Sullivan (1948) and Loosanoff et al. (1966) were used for identification of bivalve genera in this study. Although somewhat subjective, regular use of this method provided reliable identification of bivalve genera. Size and shape of larval bivalve veliconchal shells vary considerably (Jørgensen, 1946; Loosanoff \& Davis, 1963; Bayne, 1965), but the detailed descriptions of the shell morphology of $M$. edulis (Sullivan, 1948; Loosanoff et al., 1966; de Schweinitz \& Lutz, 1976; Fuller \& Lutz, 1989) made identification of this species relatively easy.

The planktic species diversity and temporal occurrence of bivalves found in this study are similar to descriptions of North Sea plankton by Kändler (1926), Werner (1940), Rees (1954) and Heiber (1988). However, whereas these authors reported a dominance of $M$. edulis larvae throughout the year, Ensis americanus was found to be the most abundant of the bivalve larvae encountered in the Schleswig-Holstein Wadden Sea. Heiber (1988) found Ensis to be sub-dominant in the plankton of the Weser estuary, and its dominance over the entire period of this study suggests a possible increase in this species in the Wadden Sea fauna.

In contrast to the almost total absence of Cerastoderma in the present study, Heiber (1988) found up to 1300 cockle larvae per $\mathrm{m}^{3}$ in the Lower Saxony Wadden Sea. Adult $C$. edule have the highest biomass of the Wadden Sea bivalves, followed by $M$. edulis and E. americanus (Ruth, Institut für Meereskunde, Kiel, pers.comm.). The low abundance of cockle larvae in the Schleswig-Holstein samples is therefore strange. The strong turbulent currents at maximal tidal exchange (mid-way between high and low tides) in the Wadden Sea tidal channels appear to cause complete mixing of the water column within these channels. Turbulent eddies, carrying large quantities of bottom sediment and detritus, were often observed reaching the surface during sampling. Surface plankton samples also contained large quantities of sand particles (up to $300 \mu \mathrm{m}$ diameter), indicating homogeneous mixing of tidally suspended bottom sediments. Samples taken at the surface during the maximal ebb current are therefore probably representative of the distribution of bivalve larvae in the entire tidal stream and associated water masses. Reliance on surface sampling was also justified by the insignificant differences in larval abundances between the surface and oblique-haul samples. 
It is, however, possible that $C$. edule larvae specifically shelter in areas inaccessible to the bongo-net sampling techniques used, such as in calmer seabed eddies, or a seabed boundary layer. For example, Jonsson et al. (1991) found that, when water velocities exceed $>5 \mathrm{~cm} \cdot \mathrm{s}^{-2}$, cockle larvae become confined to a slowly drifting seabed boundary layer, and are unable to enter the water column above. Alternately, cockle larval abundance may have been underestimated due to difficulties with identification. Problems with the laboratory culture of cockle larvae (Seaman, Institut für Meereskunde, Kiel, pers. comm.) have resulted in a lack of reliable larval descriptions in the literature, complicating identification. Resolution of these questions requires further work on cockle larval identification and distribution.

Mileikovsky (1973) reported the ability of the larvae of many bivalve taxa to regulate their position in the water column by means of active vertical movement. Although larval densities in oblique hauls in this study were not significantly different from surface samples, there have been indications that limited accumulation of $M$. edulis larvae may persist near the surface in strongly flowing ebb currents, provided turbulence is not strong enough to mix the water column. For example, Verwey (1966) and Buyanovskii \& Kulinova (1984) reported concentrations of larger larvae (195-235 $\mu \mathrm{m})$ in the upper water layers at high current velocities, when smaller veliger larvae $(<185 \mu \mathrm{m}$ ) were evenly distributed throughout the water column. However, strong vertical turbulence, such as occurs during maximal tidal exchange in the Wadden Sea, results in mixing of even the larger larvae.

The Schleswig-Holstein mussel stocks are concentrated in the north Frisian region of the Wadden Sea. High tidal ranges and resultant strong currents cause rapid and fairly homogeneous distribution of larvae, resulting in the similarity of larval densities at different sites around the island of Amrum. It is likely that plankton samples from the vicinity of the Eiderstedt peninsula, or from waddens to the north of Sylt island, will show noticeable differences from those of Schleswig-Holstein, as the bivalve species diversity and $M$. edulis biomass are very different in these regions.

Significant annual variations in larval densities from adjacent areas of similar biomass are not uncommon. For example, maximum reported densities of 7000 individuals per $\mathrm{m}^{3}$ in the Dutch Wadden Sea (Binsbergen, RIN-DLO, unpubl.) and 9000 larvae per $\mathrm{m}^{3}$ in Lower Saxony plankton (Heiber, 1988) differ by nearly one order of magnitude from the range of numbers found in this study, even when averaged over the period of highest occurrence (May-September). Such extreme variations are thought to result primarily from environmentally induced fluctuations in spawning duration and intensity, rather than from variations in biomass of the adult populations (Jørgensen, 1981). Severe winter temperatures cause a marked decrease in basal metabolism, resulting in reduced depletion of energy reserves and an increase in gamete production when temperatures increase. Temperature increases in spring are more rapid after such winters, resulting in synchronous and more intense spawning of the stocks. Meteorological records show that the winters $1975 / 76$ and 1981/82, preceding the studies of Binsbergen (RIN-DLO, unpubl.) and Heiber (1988) respectively, were characterized by below-average winter temperatures (Deutscher Wetterdienst, 1975-1982), which was not the case in the present study. Limited sample numbers and patchy plankton distributions may, however, also lead to increased variability between localities and sampling periods. 
The temperature and chlorophyll-a concentrations measured near the Norderaue plankton station (Fig. 9) show the close relationship between larval abundance maxima and phytoplankton blooms during summer (Göbel, in prep.). Furthermore, the temporal relationship between $M$. edulis larval abundance peaks and parent-stock spawning events appears to be relatively consistent (see also Bayne, 1964; Seed, 1969; Heiber, 1988). The continuous presence of $M$. edulis larvae in the plankton substantiates extended spawning seasons in the adult populations. In comparison with cycles in gonad index and condition index (Pulfrich, in prep.), the larval abundance peaks occur somewhat later than spawning events. In the spring, peak larval densities occur 1-2 weeks after spawning, corresponding to the normal time for development from the veliger to the velichoncha (Loosanoff \& Davis, 1963). Larval development after the autumn spawning appears to take slightly longer, presumably as a result of the declining water temperatures and reduced phytoplankton concentrations. Gonad activity observed in August (Pulfrich, in prep.) was only reflected in larval abundance 4 weeks later. Moreover, their presence throughout the winter shows that larvae can delay metamorphosis during unfavourable conditions.

The October/November spawnings of the low intertidal and subtidal populations (Pulfrich, in prep.) were not well represented in the concurrent plankton samples. Larval

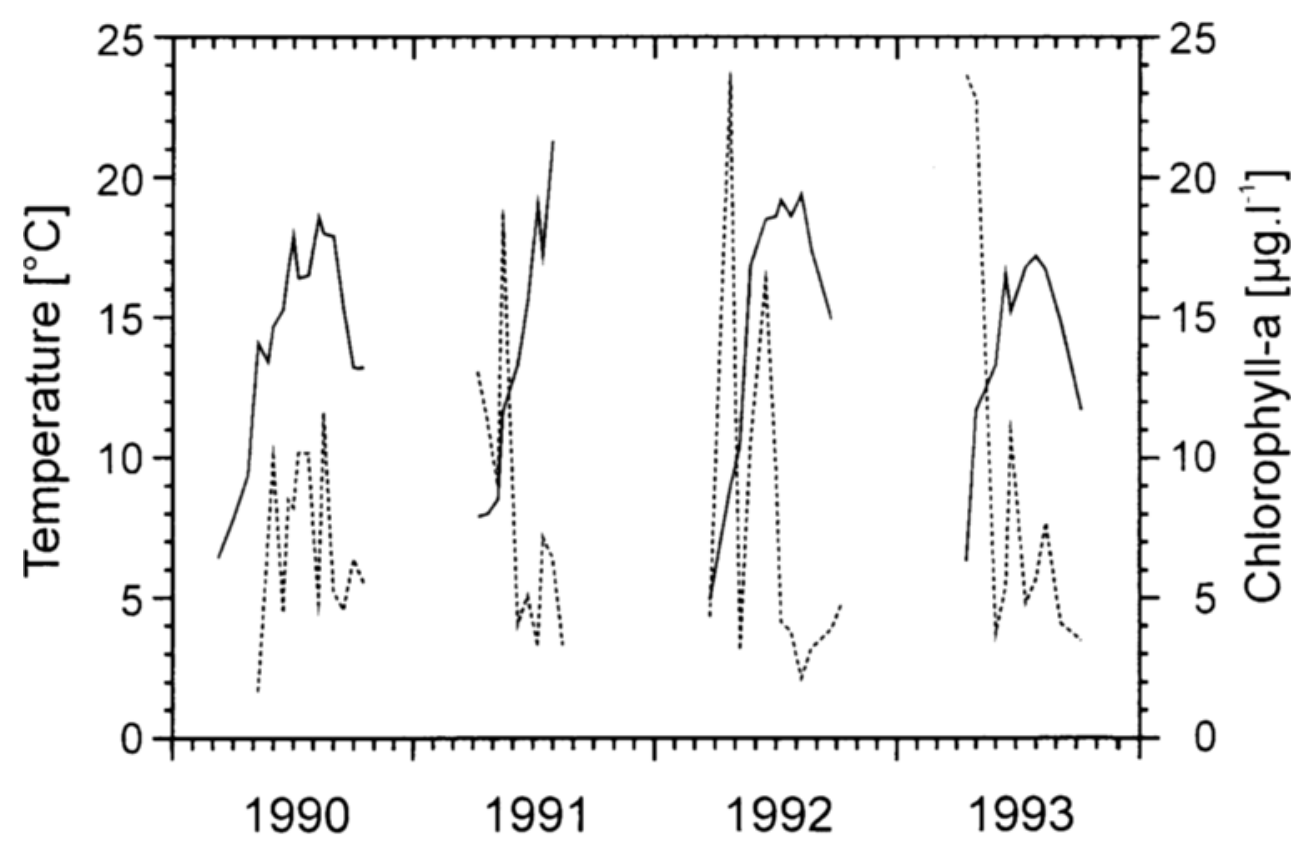

\section{- Temperature $\quad$-....... Chlorophyll-a}

Fig. 9. Mean sea surface temperature and chlorophyll-a concentrations in the Norderaue tidal stream. Data from regular aerial surveys to monitor phytoplankton development and blooms in the Wadden Sea (Göbel, in prep.) 
densities subsequently increased during January/February. This increase could not, however, be associated with any local spawning event. As mussel egg cleavage does not occur below $5^{\circ} \mathrm{C}$ (Bayne, 1965), and winter water temperatures in the study area are typically below this, these abundance peaks are thought to represent the appearance in the plankton of larvae with a prolonged pediveliger stage. Delay in metamorphosis is characterized by a cessation of feeding and growth for periods of up to 6 months (Lane et al., 1985), and is triggered by reduced temperature, rather than reduced food availability (Bayne, 1965).

The correlation between periods of gamete release and subsequent larval abundances in the plankton suggests that the majority of mussel larvae encountered in the plankton in this area result from local spawning. However, the larval abundance peaks observed in July 1991 and August 1992 (Fig. 4) were observed too early to result irom local spawning (Pulfrich, in prep.). The larval densities were also too high to be attributable to the low-level, year-round spawning of a small proportion of the stock. This suggests an immigration of larvae from adjacent regions in the North Sea. These imported larvae either delay metamorphosis during transport in offshore waters, where phytoplankton biomass and temperatures are lower, or are post-larvae which have previously undergone primary attachment on suitable substrates in deeper waters.

The occasional appearance in the plankton of bivalve species foreign to the area (e. g. the saddle mussel Anomia ephippium) confirms the incursion of pelagic larvae transported from distant locations. Sprung (1983) found the spawning season of $M$. edulis on Helgoland to extend from April to June. Although dependent on prevailing wind regimes, the duration for a particle drifting in surface currents from Helgoland to Amrum is estimated at 4-8 weeks (Schrumm, University Hamburg, pers. comm.). The arrival of such larvae would therefore correspond to the unexplained larval abundance peaks observed in this study during July and August. Another possible source of imported larvae could be the mussel stocks off the coast of Lower Saxony. The proportion of larvae imported into the region is difficult to determine, but could be investigated by comparison of daily shell increments with spawning events in local populations.

Planktic larval abundances generally decline with increasing distance offshore (Werner, 1940; Mileikovsky, 1968). A series of plankton samples taken $10 \mathrm{~km}$ seaward of the Norderaue station during the larval peak in June 1990 (Westvortrapptief, Fig. 1) showed that the density of bivalve larvae in the offshore waters was only $12 \%$ of that at the inshore stations. In contrast, Rees (1954) reported large concentrations of $M$. edulis larvae in the middle of the North Sea. Those larvae were at advanced stages of development, confirming their teleplanic nature and their ability to disperse over large distances in ocean currents (Scheltema, 1971).

Although monthly samples give a picture of the overall cyclic patterns of plankton abundance, the mussel larval developmental period of $3-4$ weeks at $16-20^{\circ} \mathrm{C}$ can result in abundance peaks being missed, or in poor estimates of larval densities. The higher resolution of fortnightly samples is needed to follow successive spawning events, from appearance of bivalve veliconcha to their disappearance as pediveligers, and to allow for detection of incursion of cohorts from other habitats.

The dispersive planktic phase of bivalve larvae is, however, subject to selection pressures exerted by a wide variety of bio-physical factors. Larval survival and development is dependent upon species-specific temperature and turbidity ranges, and markedly af- 
fected by fluctuations in food abundance, food quality and predator abundance. These biotic and abiotic parameters affect various larval species differently, and resultant interannual variations in the composition of larval stocks surviving to metamorphosis can markedly influence benthic community composition and structure (Thorson, 1966; Osman, 1977; Okamura, 1986). For example, intense filtration by large stocks of resident bivalve species, or a series of unusually strong recruitments of planktivorous predators, may explain the low larval densities in Schleswig-Holstein in comparison with other areas. Sporadic importation of larvae from the North Sea could also contribute to fluctuations in larval abundance, despite relatively stable local mussel populations. Whereas plankton samples remain a useful means of confirming spawning events of the local adult populations, the described factors all combine to make prediction of recruitment to adult mussel stocks from larval densities unreliable.

Acknowledgements. This study formed part of an extensive 5-year research programme initiated in 1989. The programme "Ecosystem Research Wadden Sea" was funded by the Federal Environmental Agency and the state of Schleswig-Holstein. I am indebted to my colleague Maarten Ruth, without whose unparalleled knowledge of the area and participation in the collection of samples this study would not have been possible. The diligent assistance of many students in the processing of the sample material is greatly acknowledged; particular thanks are due to Brigitte Borkowitz, Sandra Hierse, Stefanie Pollit, Ralf Schmidt and Martina Schwarzer for their long-standing, untiring and cheerful enthusiasm.

\section{LITERATURE CITED}

Bayne, B. L., 1964. Primary and secondary settlement in Mytilus edulis L. (Mollusca). - J. Anim. Ecol. $33,513-523$.

Bayne, B. L., 1965. Growth and delay of metamorphosis of the larvae of Mytilus edulis (L.). - Ophelia $2,1-47$.

Bayne, B. L., 1976. The biology of mussel larvae. In: Marine mussels: their ecology and physiology. Ed. by B. L. Bayne. Cambridge Univ. Press, London, 81-120.

Bhattacharya, C. G., 1967. A simple method of resolution of a distribution into Gaussian components. - Biometrics 23, 115-135.

Buyanovskii, A. I. \& Kulikova, V. A., 1984. Planktonic distribution of Mytilus edulis larvae and their settlement on collectors in Vostok Bay, Sea of Japan. - Sov. J. mar. Biol. 10(6), 350-354.

Deutscher Wetterdienst, 1975. Monatlicher Witterungsbericht 23(10).

Deutscher Wetterdienst, 1976. Monatlicher Witterungsbericht 24(11).

Deutscher Wetterdienst, 1981. Monatlicher Witterungsbericht 29(12).

Deutscher Wetterdienst, 1982. Monatlicher Witterungsbericht 30(13).

Fuller, S. C. \& Lutz, R. A., 1989. Shell morphology of larval and post-larval mytilids from the NorthWestern Atlantic. - J. mar. biol. Ass. U. K. 69, 181-218.

Gayanilo, F. C., Soriano, M. \& Pauly, D., 1989. A draft guide to the Compleat ELEFAN. - ICLARM Software 2,1-70.

Heiber, W., 1988. Die Faunengemeinschaft einer großen Stromrinne des Wurster Wattengebietes (Deutsche Bucht). Diss. Univ. Bonn, Bonn, 399 pp.

Høisaeter, T., 1986. An annotated check-list of marine molluscs of the Norwegian coast and adjacent waters. - Sarsia 71, 73-145.

Jonsson, P. R., André, C. \& Lindegarth, M., 1991. Swimming behaviour of marine bivalve larvae in a flume boundary-layer flow: evidence for near-bottom confinement. - Mar. Ecol. Prog. Ser. 79, $67-76$.

Jørgensen, C. B., 1946. Reproduction and development of Danish marine bottom invertebrates. 9. Lamellibranchia. - Meddr Kommn Danm. Fisk.- og Havunders. (Plankton) 4, 277-311.

Jørgensen, C. B., 1981. Mortality, growth, and grazing impact of a cohort of bivalve larvae, Mytilus edulis L. - Ophelia 20, 185-192. 
Kändler, R., 1926. Muschellarven aus dem Helgoländer Plankton. - Wiss. Meeresunters. (Helgoland) $16,1-8$.

Lane, D. J. W., Beaumont, A. R. \& Hunter, J. R., 1985. Byssus drifting and the drifting threads of the young post larval mussel (Mytilus edulis). - Mar. Biol. 84, 301-308.

Loosanoff, V. L. \& Davis, H. C., 1963. Rearing of bivalve molluscs. - Adv. mar. Biol, 1, 1-136.

Loosanoff, V. L., Davis, H. C. \& Chanley, P. E., 1966. Dimensions and shapes of some marine bivalve molluscs. - Malacologia 4, 351-435.

Lutz, R. A. \& Kennish, M. J., 1992. Ecology and morphology of larval and early postlarval mussels. In: The mussel Mytilus: ecology, physiology, genetics and culture. Ed. by E. Gosling. Elsevier, Amsterdam, 53-86.

Mileikovsky, S. A., 1968. Some common features in the drift of pelagic larvae and juvenile stages of bottom invertebrates with marine currents in temperate regions. - Sarsia 34, 209-216.

Mileikovsky, S. A., 1973. Speed of active movement of pelagic larvae of marine bottom invertebrates and their ability to regulate their vertical position. - Mar. Biol. 23, 11-17.

Miyazaki, I., 1962. On the identification of lamellibranch larvae. - Bull. jap. Soc. scient. Fish. 28, $955-966$

Nelson, T. C., 1928. Pelagic dissoconchs of the common mussel. Mytilus edulis, with observations on the behavior of the larvae of allied genera. - Biol. Bull. mar. biol. Lab. Woods Hole 55, 180-192.

Okamura, B., 1986. Formation and disruption of aggregations of Mytilus edulis in the fouling community of San Francisco Bay, California. - Mar. Ecol. Prog. Ser. 30, 275-282.

Osman, R. W., 1977. The establishment and development of a marine epifaunal community. - Ecol. Monogr. 47, 37-63.

Postma, H. 1982. Hydrography of the Wadden Sea: Movements and properties of water and particulate matter. In: Ecology of the Wadden Sea. Ed. by W. J. Wolff. Balkema, Rotterdam, 1(2), 1-75.

Rees, C. B., 1950. The identification and classification of lamellibranch larvae. - Hull Bull. mar. Ecol. $3,73-104$

Rees, C. B., 1954. Continuous plankton records: the distribution of lamellibranch larvae in the North Sed. - Bull. mar. Ecol. 4, 21-27.

Scheltema, R. S., 1971. The dispersal of the larvae of shoal-water benthic invertebrate species over long distances by ocean currents. In: Fourth European marine biological symposium. Ed. by D. J. Crisp. Cambridge Univ. Press, London, 7-28.

Schweinitz, E. H. de, \& Lutz, R. A., 1976. Larval development of the northern horse mussel Modiolus modiolus (L.) including a comparison with the larvae of Mytilus edulis L. as an aid in planktonic identification. - Biol. Bull mar. biol Lab. Woods Hole 150, 348-360.

Seed, R., 1969. The ecology of Mytilus edulis L. (Lamellibranchiata) on exposed rocky shores. I. Breeding and settlement. - Oecologia 3, 277-316.

Sprung, M., 1983. Reproduction and fecundity of the mussel Mytilus edulis at Helgoland (North Sea). - Helgoländer Meeresunters. 36, 243-255.

Stafford, J., 1912. On the recognition of bivalve larvae in plankton collections. - Contr. Can. Biol. 1906-1910, 221-242.

Sullivan, C. M., 1948. Bivalve larvae of Malpeque Bay, P.E.I. - Bull. Fish. Res. Bd Can. 77, 1-36.

Thorson, G., 1946. Reproduction and development of Danish marine bottom invertebrates. - Meddr Kommn Danm. Fisk. - og Havunders. (Plankton) 4, 1-524.

Thorson, G., 1966. Some factors influencing the recruitment and establishment of marine benthic communities. - Neth. J. Sea Res. 3, 267-293.

Verwey, J., 1966. The role of some external factors in the vertical migration of marine animals. - Neth. J. Sea Res. 3, 245-266.

Werner, B., 1940. Über die Entwicklung und Artunterscheidung von Muschellarven des Nordseeplanktons, unter gesonderter Berücksichtigung der Schalenentwicklung. - Zool. Jb. (Anat. Ontogenie Tiere) $66,1-54$.

Widdows, J., 1991. Physiological ecology of mussel larvae. - Aquaculture 94, 147-163. 